\title{
2 The Effect of Educational Intervention on Family \\ 3 Caregivers' Perceived Threat of the Risk of 4 Dependence among Patients with Stroke
}

Narjes Deyhoul ${ }^{1}$, Parvaneh Vasli ${ }^{2, *}$, Camelia Rohani ${ }^{3}$, Nezhat Shakeri ${ }^{4}$ and Meimanat Hosseini ${ }^{5}$

1. MSN, School Of Nursing and Midwifery, Shahid Beheshti University of Medical Sciences, Tehran, Iran; narges.dyhl@gmail.com

2. Ph.D., Assistant Professor, School of Nursing and Midwifery, Shahid Beheshti University of Medial Sciences, Tehran, Iran; p-vasli@sbmu.ac.ir

3. Ph.D., Assistant Professor, School of Nursing and Midwifery, Shahid Beheshti University of Medial Sciences, Tehran, Iran; cameliarohani@sbmu.ac.ir

4. Ph.D., Assistant Professor, School of Paramedical Sciences, Shahid Beheshti University of Medial Sciences, Tehran, Iran; nezhat2000@yahoo.com

5. Ph.D., Assistant Professor, School of Nursing and Midwifery, Shahid Beheshti University of Medial Sciences, Tehran, Iran; meimanathosseini@yahoo.com

* Correspondence: p-vasli@sbmu.ac.ir; Tel.: +982188566567

Abstract: 1) Background: The present study aimed to examine the effect of the instructional intervention in family caregivers' perceived threat of stroke patients' dependency risk. 2) Methods: This was a randomized controlled clinical trial in which two patient and family caregiver groups of 45 were randomly divided into intervention and control groups based on the inclusion/exclusion criteria. Instructional intervention for family caregivers in the intervention group was in the form of four one-hour sessions. The data were collected before and immediately after instructional intervention at the hospital as well as two weeks and two months following the intervention via postal service. The data analysis was done using SPSS ver.22.3) Results: The pre-intervention family caregivers' perceived threat was not significantly different in the two groups $(P=0.591)$. However, the family caregivers' perceived threat of the intervention group increased after the intervention compared with the control group $(\mathrm{P}<0.001)$. In addition, the family caregivers' perceived threat of the intervention group was significantly different in all post instructional intervention stages compared with pre-intervention $(\mathrm{P}<0.001)$, whereas no such difference was observed in the control group ( $\mathrm{p}=0.245) .4$ ) Conclusions: It is recommended that stroke patients' caregivers be provided with instructional programs to enhance their understanding of patient dependency risks and challenges.

Keywords: instruction; perceived threat; caregivers; stroke; dependency

\section{Introduction}

Stroke is a sudden and localized neurological defect due to ischemic/hemorrhagic lesions in the brain that last for over 24 hours partially affecting the body function and altering the physical perception of the body's condition [1]. The global annual incidence of stroke was estimated to fall on a continuum with 41,316, and 139-149 individuals per 100,000 of the populations respectively in Nigeria, Tanzania, and Iran as the populations grow older [2,3].

Stroke is the main cause of adult inability and dependency on caregiver in performing ADLs [4]. Despite medical advancements, stroke patients are often in need of significant help from their 
caregivers in their ADLs [5]. According to estimations, $62 \%$ of stroke patients will become dependent on others [6]. Family caregivers constitute a major part of care providers to stroke patients. A family caregiver is regarded as a friend or family member who offers free help to a chronically ill patient. In 2009, about 66 million Americans (three out of ten households) reported care provision by at least one family caregiver [7].

The majority of Iranian families assume the major caring responsibility for their patients due to high costs of private center/home nursing, inadequate numbers of state-funded rehabilitation centers, and the lack of post-discharge follow-up [8]. These patients are highly dependent on their respective family caregivers for their ADLs [9]. Studies showed that the caregivers of such patients experienced high levels of dependency-induced caring pressure and, consequently, physical-psychological problems [10-12]. Therefore, family caregivers and patients would both benefit from diminished dependency levels. Independent ADLs enhances stroke patients' quality of life [9]. Accordingly, empowering help-seekers to gain independence and strive for non-reliance is part of the caring responsibilities of healthcare providers in modern caring sciences [13].

One of the major steps toward achieving greater patient independence and diminished caring pressure on family caregivers is the reinforcement of their perceived threat (PT) compared to the stroke patients' dependency risk in ADLs [14]. According to health behavioral prediction theories, people are capable of preventing health-threatening behaviors when they feel such threats [14, 15]. The PT is, in fact, the most basic motivation and driving force for health-related behaviors [16]. As a constituent of health models, PT comprises two components namely perceived sensitivity (PS) and perceived intensity (PI). The PT also involves individual beliefs about a health-threatening problem [17].

The PS refers to an individual belief about the development of a particular disease or suffering a harmful condition due to a specific behavior. The PI is the extent of damage induced by the development of a disease or a harmful condition resulted from a specific behavior [14, 18]. The PT is reinforced when caregivers expand their knowledge and perspective about the causes, symptoms, complications, preventive measures and treatments of a disease, consider the probability of disease development on their part, understand the significance of disease threats and complications, adopt a positive attitude toward disease prevention, and have adequate motivation to participate [19]. Accordingly, the PT of the dependency risk for patients can be altered by offering family-oriented counseling and instructional programs to family caregivers contributing to the diminishment of caregiver burden and stress and the facilitation of patient recovery [20].

Numerous studies were conducted in Iran on the effect of instructional intervention on PT in various areas such as the understanding of ostomy children's parents, myocardial infarction patients' quality of life [21], the quality of life of asthmatic children's parents [22], self-efficacy and self-esteem of patients undergoing coronary artery bypass surgery [23], and the skill, belief, and knowledge of multiple sclerosis patients' family caregivers [24]. However, the researchers were unable to find any study on the effect of the instructional intervention on family caregivers' PT of stroke patient dependency risk despite the high prevalence of stroke in Iran. The present study was therefore conducted to fill this gap. It is hoped that the study results help to improve the healthcare services and the individual and familial performance of these patients.

\section{Materials and Methods}

This was a randomized controlled clinical trial in which the effect of the instructional intervention on family caregivers' PT of stroke patient dependency risk was evaluated. Data were collected from July 2016 to March 2017 from the departments of neurology in the hospitals of Shahid Beheshti University of Medical Sciences (SBMU) in Tehran, Iran. Based on the study by Azimi R et al. [25], and using the following sample size determination formula: 
Two patient and family caregiver groups of 45 (90 patients and 90 family caregivers in total) were calculated in the study. The inclusion criteria were a minimum 4-day length of stay (LOS) at the departments of neurology following definitive diagnosis of stroke and continuous family care delivery. The exclusion criteria involved post-discharge readmission and demise before final evaluation. The inclusion criteria for family caregivers were lack of a history of care delivery for chronically ill patients, lack of academic instruction in medical sciences, ages over 18, and ability to complete questionnaires and make phone calls. The exclusion criterion was changing the family caregivers. A total of 118 subjects were initially included in both intervention and control groups. Fifteen and twelve subjects were respectively eliminated from the control and intervention groups based on the exclusion criteria. Two patient and family caregiver groups of 45 were finally selected as the study sample. The subjects were randomly assigned to either of intervention and control groups through coin flipping. The subjects in intervention and control groups were homogenized in groups in terms of gender, patient age, and caregiver age.

Intervention, in this study, referred to the instructional program offered to stroke patient caregivers in order to alter their PT of patient dependency risk. After the assignment of each patient-family caregiver pair to either of intervention and control groups, the questionnaires were administered to caregivers to be completed as a pretest. Relevant instructional materials to PS and PIand of patient dependency risk were then presented to caregivers in the intervention group including the definition, symptoms, risk factors, prevention, treatment, and complications of stroke as well as the negative impacts of patient family caregiver-dependency such as losing independence in ADLs and physicalpsychological stress endured by family caregivers. The presentation was face-to-face and included instructional (PowerPoint) slides and Question \& Ask sessions held by the first researcher in the form of four one-hour sessions in four consecutive days. Family caregivers were asked to complete the questionnaires through self-report before and immediately after intervention at the hospital (four days after the pretest, in the control group case) and two weeks and two months after intervention at home and mail them to the first researcher's address in accordance with the pre-planned agreements. It should be noted that the first researcher was assured of the continued presence of intervention and control subjects in the study through a number of phone calls.

Research instruments included two researcher-made questionnaires. The first questionnaire included 24 items developed to elicit demographic and clinical information. Items 1-8 and 9-24 were related to family caregivers and patients, respectively. The demographic information for patients and caregivers included gender, age, instruction, marital status, job, income adequacy, kinship relationship, and development of chronic diseases.

The second questionnaire included 20 items and was related to the PT. Items 1-10 were developed to measure the PS, i.e., family caregivers' mental understanding of the patient dependency risk in ADLs, and items 11-20 were designed to measure the PI, i.e., family caregivers' mental understanding of the extent of damage induced by patient's dependency on family caregiver in ADLs. The items were developed on a 5-point Likert scale ranging from "completely agree" to "completely disagree" and were directly scored on a score range of 1-5. The minimum and maximum scores were 20 and 100, respectively.

The face and content validity of the Perceived Threat Questionnaire were measured by distributing it to ten family caregivers and ten faculty members of the School of Nursing and Midwifery as the team of specialists. Necessary modifications were made based on their viewpoint about the clarity and intelligibility of the items. The necessity of (the inclusion of) each item was assessed by CVR, with all items scoring above 0.7 . The relevance of the items was verified using CVI, with a calculated mean of 0.8 . The internal consistency and test-retest reliability methods were used to examine the reliability of questionnaires. The questionnaire was re-administered to 20 stroke patient caregivers 
138 with a 14-day interval, achieving a correlation coefficient of $0.87(\mathrm{r}=0.87)$. The internal consistency 139 was measured through Cronbach's alpha $(\alpha=0.90)$ indicating the adequate reliability of 140 questionnaires.

141 The data were analyzed using SPSS ver.22. Descriptive statistics such as mean and standard 142 deviation, and inferential statistics including the independent-samples t-test, chi-square, Fisher's 143 exact, Mann-Whitney U, and Friedman tests were used to analyze the data. The data normality was 144 evaluated using the Kolmogorov-Smirnov test. The significance level of the findings was considered $145 \mathrm{P}<0.05$.

147 This research project was approved by the Ethics Committee of Shahid Beheshti University of 148 Medical Sciences and the Iranian Registry of Clinical Trials (IRCT) with the codes 149 IR.SBMU.PHNM.0995.990 and IRCT2017071835170N1, respectively. The data were collected after 150 presenting the letter of introduction to the authorities of the selected hospitals and explaining the 151 study objective and design to the respective matrons, the nursing staff at the departments of 152 neurology, and research departments from which the informed consent form was obtained. In 153 addition, research departments were informed of the confidentiality of patient information, the 154 voluntary nature of participation, and the right to leave the study at any time.

\section{3. Results}

The mean age of family caregivers in the intervention and control groups was calculated $41.1 \pm 11$ and $40.6 \pm 11.7$ years, respectively. The mean age of patients in the intervention and control groups was calculated $67.2 \pm 12.0$ and $66.8 \pm 11.1$ years, respectively. The mean ages of patients and caregivers were not significantly different in intervention and control groups $(\mathrm{P}=0.841$, and $\mathrm{P}=0.863$,

160 respectively). Other demographic characteristics of patients and caregivers are presented in Tables 1 161 and 2, respectively.

Table 1- Demographic and clinical characteristics of patients with stroke $\left(n_{1}=n_{2}=45\right)$

\begin{tabular}{llllll}
\hline Group & & Intervention & Control & Test results* \\
\cline { 1 - 3 } Variable & Condition & Percent & Percent & Chi-square $(\chi 2)$ & \\
& & (Number) & (Number) & Mann-whitney & (U) \\
& & & Fisher's Exact Test (FET)
\end{tabular}

\begin{tabular}{|c|c|c|c|c|c|c|}
\hline \multirow[t]{2}{*}{ Sex } & Female & 23 & $(51 / 1)$ & 14 & $(31 / 1)$ & $\chi 2=3 / 717$ \\
\hline & Male & \multicolumn{2}{|c|}{$22(48 / 9)$} & \multicolumn{2}{|l|}{$31(68 / 9)$} & $\mathrm{p}=0 / 054$ \\
\hline \multirow[t]{4}{*}{ Education } & Illiterate & 22 & $(48 / 9)$ & 16 & $(35 / 6)$ & $\mathrm{U}=796 / 000$ \\
\hline & Elementary & 16 & $(35 / 6)$ & 13 & $(28 / 9)$ & $\mathrm{p}=0 / 063$ \\
\hline & High school & 6 & $(13 / 3)$ & 14 & $(31 / 1)$ & \\
\hline & Academic & $1(2 / 2)$ & & $2(4 / 4)$ & & \\
\hline \multirow{4}{*}{$\begin{array}{l}\text { Marital } \\
\text { status }\end{array}$} & Single & 0 & $(0)$ & 2 & $(4 / 4)$ & $\mathrm{FET}=4 / 288$ \\
\hline & Married & 31 & $(68 / 9)$ & 35 & $(77 / 8)$ & $\mathrm{p}=0 / 175$ \\
\hline & Divorced & 2 & $(4 / 4)$ & 0 & $(0)$ & \\
\hline & Widowed & \multicolumn{2}{|c|}{$12(26 / 7)$} & \multicolumn{2}{|l|}{$8(17 / 8)$} & \\
\hline \multirow{3}{*}{$\begin{array}{l}\text { Employment } \\
\text { status }\end{array}$} & Housekeeper & 21 & $(46 / 7)$ & 14 & $(31 / 1)$ & $\chi 2=4 / 505$ \\
\hline & Employed & 11 & $(24 / 4)$ & 9 & $(20 / 0)$ & $\mathrm{p}=0 / 342$ \\
\hline & Retired & 9 & $(20 / 0)$ & 14 & $(31 / 1)$ & \\
\hline
\end{tabular}




\begin{tabular}{|c|c|c|c|c|}
\hline & Unemployed & $(8 / 9)$ & $(15 / 6)$ & \\
\hline & Other & $0(0)$ & $1(2 / 2)$ & \\
\hline \multirow{2}{*}{$\begin{array}{l}\text { Income } \\
\text { adequacy }\end{array}$} & Adequate & $(40 / 0)$ & $(33 / 3)$ & $\chi 2=0 / 431$ \\
\hline & Inadequate & $27(60 / 0)$ & $30(66 / 7)$ & $\mathrm{p}=0 / 512$ \\
\hline Chronic & Yes & $36(80 / 0)$ & $37(82 / 2)$ & $\chi 2=0 / 073$ \\
\hline illness $* *$ & No & $9(20 / 0)$ & $8(17 / 8)$ & $\mathrm{p}=0 / 788$ \\
\hline
\end{tabular}

*Significance level: $\mathbf{p}<0 / 05$, ** Diabetes, Hypertension, Hypercholesterolemia

162

Table 2- Demographic and clinical characteristics of family caregivers $\left(n_{1}=n_{2}=45\right)$

\begin{tabular}{llllll}
\hline Group & & Intervention & Control & Test results* \\
\cline { 1 - 2 } Variable & Condition & Percent & Percent & Chi-square $(\chi 2)$ & \\
& & (Number) & (Number) & Mann-whitney & (U) \\
& & & Fisher's Exact Test (FET)
\end{tabular}

\begin{tabular}{|c|c|c|c|c|c|c|}
\hline \multirow[t]{2}{*}{ Sex } & Female & 33 & $(73 / 3)$ & 25 & $(55 / 6)$ & \multirow[t]{2}{*}{$\chi 2=3 / 103$} \\
\hline & Male & \multicolumn{2}{|c|}{$12(26 / 7)$} & \multicolumn{2}{|c|}{$20(44 / 4)$} & \\
\hline \multirow[t]{4}{*}{ Education } & Illiterate & 8 & $(17 / 8)$ & 6 & $(13 / 3)$ & $U=969 / 50$ \\
\hline & Elementary & 23 & $(51 / 1)$ & 29 & $(64 / 5)$ & $\mathrm{p}=0 / 695$ \\
\hline & High school & \multicolumn{2}{|c|}{$14(31 / 1)$} & \multicolumn{2}{|c|}{$10(22 / 2)$} & \\
\hline & Academic & & & & & \\
\hline \multirow{4}{*}{$\begin{array}{l}\text { Marital } \\
\text { status }\end{array}$} & Single & 9 & $(20 / 0)$ & 15 & $(33 / 3)$ & $\mathrm{FET}=3 / 661$ \\
\hline & Married & 32 & $(71 / 1)$ & 29 & $(64 / 4)$ & $\mathrm{p}=0 / 283$ \\
\hline & Divorced & 2 & $(4 / 4)$ & 1 & $(2 / 2)$ & \\
\hline & Widowed & \multicolumn{2}{|c|}{$2(4 / 4)$} & \multicolumn{2}{|c|}{$0(0)$} & \\
\hline \multirow{5}{*}{$\begin{array}{l}\text { Employment } \\
\text { status }\end{array}$} & Housekeeper & 31 & $(68 / 9)$ & 18 & $(40 / 0)$ & $\mathrm{FET}=3 / 661$ \\
\hline & Employed & 10 & $(22 / 2)$ & 22 & $(48 / 9)$ & $\mathrm{p}=0 / 283$ \\
\hline & Retired & 1 & $(2 / 2)$ & 3 & $(6 / 7)$ & \\
\hline & Unemployed & 1 & $(2 / 2)$ & 1 & $(2 / 2)$ & \\
\hline & Other & \multicolumn{2}{|c|}{$2(4 / 4)$} & \multicolumn{2}{|c|}{$1(2 / 2)$} & \\
\hline \multirow{2}{*}{$\begin{array}{l}\text { Income } \\
\text { adequacy }\end{array}$} & Adequate & 23 & $(51 / 1)$ & 25 & $(55 / 6)$ & $\chi 2=0 / 179$ \\
\hline & Inadequate & \multicolumn{2}{|c|}{$22(48 / 9)$} & \multicolumn{2}{|c|}{$20(44 / 4)$} & $\mathrm{p}=0 / 673$ \\
\hline kinship & Sister & 0 & $(0)$ & 1 & $(2 / 2)$ & $\mathrm{FET}=1 / 955$ \\
\hline \multirow[t]{3}{*}{ relationship } & Brother & 0 & $(0)$ & 1 & $(2 / 2)$ & $\mathrm{p}=0 / 895$ \\
\hline & Son or daughter & 36 & $(80 / 0)$ & 34 & $(75 / 6)$ & \\
\hline & Spouse & \multicolumn{2}{|c|}{$9(20 / 0)$} & \multicolumn{2}{|c|}{$9(20 / 0)$} & \\
\hline Chronic & Yes & 12 & $(26 / 7)$ & 7 & $(15 / 6)$ & $\chi 2=1 / 668$ \\
\hline illness** & No & \multicolumn{2}{|c|}{$33(73 / 3)$} & \multicolumn{2}{|c|}{$38(84 / 4)$} & $\mathrm{p}=0 / 197$ \\
\hline
\end{tabular}

*Significance level: $\mathbf{p}<0 / 05, * *$ Diabetes, Hypertension, Hypercholesterolemia

\section{3}

According to the Tables, the majority of stroke patients were male, married, unlettered, lacked income adequacy, and suffered from chronic hypertension, diabetes, and hypercholesterolemia. The majority of caregivers were female, married, housewife, had secondary education and income adequacy and did not have the abovementioned chronic diseases. According to the results, family 
168 caregivers and patients in both intervention and control groups were homogenous in terms of other 169 demographic characteristics such as gender, education, marital status, job, and income adequacy.

170 Table 3 displays the mean and standard deviation of the PT together with its subscales including 171 the PS and PIof patients' dependency risk in the family caregivers of intervention and control groups.

\begin{tabular}{|c|c|c|c|c|c|}
\hline Variable & Group & $\begin{array}{l}\text { Before } \\
\text { intervention }\end{array}$ & $\begin{array}{l}\text { Immediately } \\
\text { after intervention }\end{array}$ & $\begin{array}{l}\text { Two weeks after } \\
\text { intervention }\end{array}$ & $\begin{array}{l}\text { Two months after } \\
\text { intervention }\end{array}$ \\
\hline \multirow{2}{*}{$\begin{array}{l}\text { Perceived threat } \\
(20-100)\end{array}$} & Intervention & $77 / 13 \pm 20 / 49$ & $97 / 08 \pm 6 / 54$ & $97 / 77 \pm 5 / 88$ & $98 / 44 \pm 3 / 77$ \\
\hline & Control & $74 / 68 \pm 20 / 06$ & $74 / 64 \pm 20 / 17$ & $72 / 97 \pm 20 / 38$ & $74 / 71 \pm 20 / 55$ \\
\hline \multirow{2}{*}{$\begin{array}{l}\text { Perceived } \\
\text { sensitivity } \\
(20-100)\end{array}$} & Intervention & $37 / 93 \pm 11 / 08$ & $48 / 44 \pm 3 / 16$ & $48 / 28 \pm 4 / 33$ & $48 / 77 \pm 2 / 58$ \\
\hline & Control & $37 / 42 \pm 10 / 95$ & $37 / 00 \pm 11 / 21$ & $36 / 48 \pm 11 / 50$ & $37 / 62 \pm 11 / 49$ \\
\hline \multirow{2}{*}{$\begin{array}{l}\text { Perceived intensity } \\
(\mathbf{2 0 - 1 0 0 )}\end{array}$} & Intervention & $39 / 20 \pm 11 / 68$ & $48 / 64 \pm 4 / 12$ & $49 / 48 \pm 1 / 82$ & $49 / 66 \pm 1 / 65$ \\
\hline & Control & $37 / 26 \pm 12 / 31$ & $37 / 64 \pm 11 / 89$ & $36 / 48 \pm 12 / 69$ & $37 / 08 \pm 12 / 48$ \\
\hline
\end{tabular}

172

The increased PT by family caregivers in the intervention group compared with those of the control group can be inferred from the mean values represented in Chart 1.

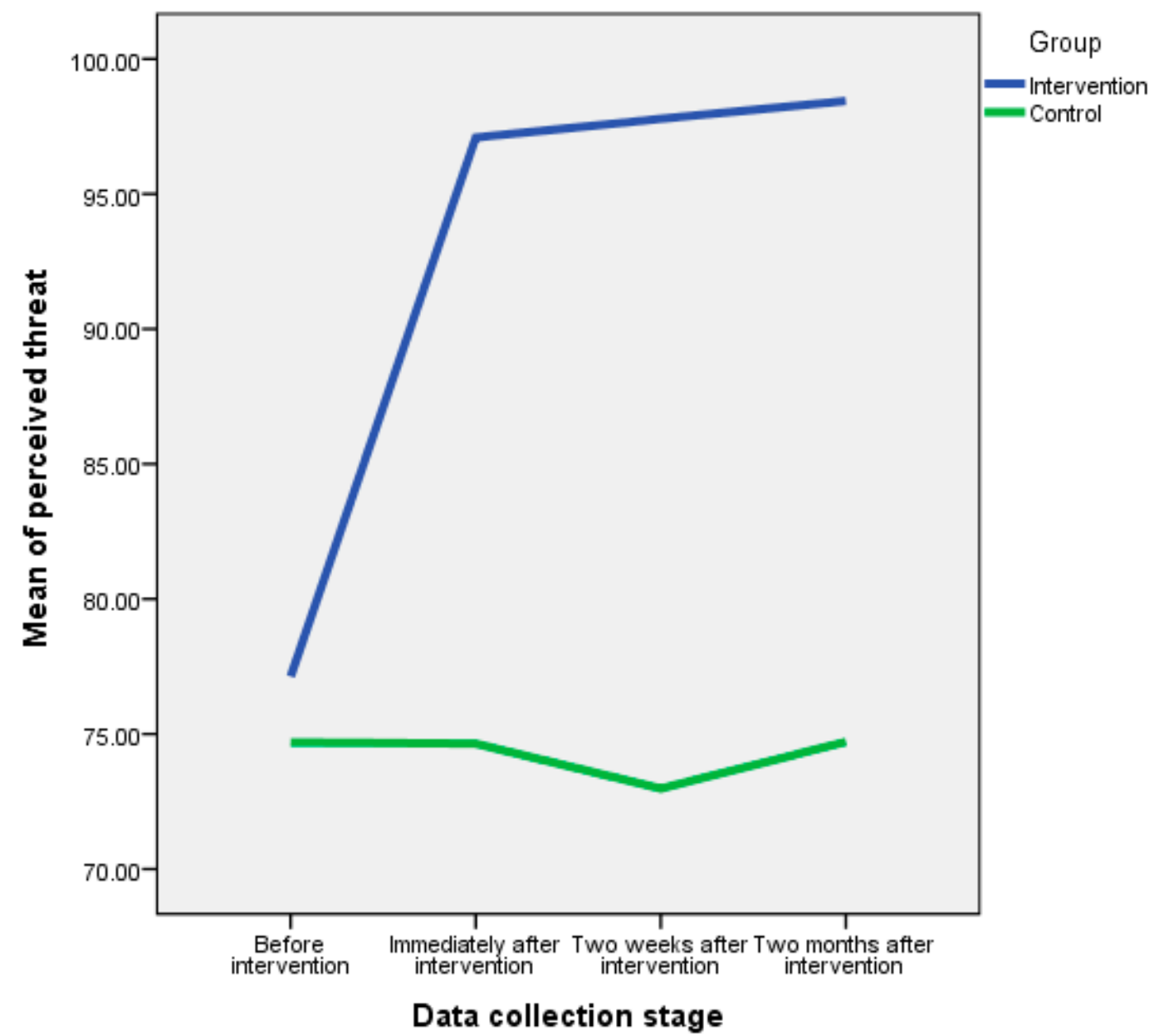

175 Chart (1). Perceived threat in intervention and control groups divided by each data collection stage 
176

177

178

Table 4 demonstrates the Friedman test results for intervention and control groups divided by each data collection stage, pointing to the significant relationship between changes in the PT by family caregivers and its subscales.

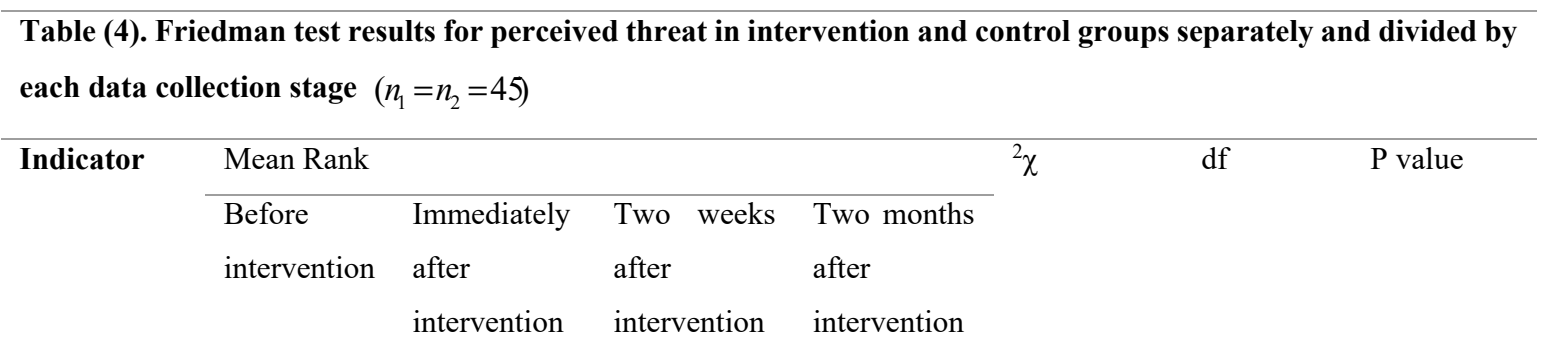

\begin{tabular}{lccccccc} 
Group & \multicolumn{1}{l}{} \\
\hline Intervention & $1 / 44$ & $2 / 82$ & $2 / 79$ & $2 / 94$ & $65 / 989$ & 3 & $<0 / 001$ \\
\hline Control & $2 / 76$ & $2 / 47$ & $2 / 29$ & $2 / 49$ & $4 / 154$ & 3 & $0 / 245$
\end{tabular}

Table 5 compares the PT scores of intervention and control groups in each data collection stage.

\begin{tabular}{|c|c|c|c|c|}
\hline Stage & $\begin{array}{l}\text { Before } \\
\text { intervention }\end{array}$ & $\begin{array}{l}\text { Immediately after } \\
\text { intervention }\end{array}$ & $\begin{array}{l}\text { Two weeks after } \\
\text { intervention }\end{array}$ & $\begin{array}{l}\text { Two months after } \\
\text { intervention }\end{array}$ \\
\hline \multicolumn{5}{|c|}{ Indicator } \\
\hline $\mathbf{U}$ & $946 / 000$ & $286 / 000$ & $211 / 500$ & $215 / 500$ \\
\hline $\mathbf{Z}$ & $-0 / 538$ & $-6 / 162$ & $-6 / 794$ & $-6 / 455$ \\
\hline P value & $0 / 591$ & $<0 / 001$ & $<0 / 001$ & $<0 / 001$ \\
\hline
\end{tabular}

\section{Discussion}

The present study aimed to examine the effect of the instructional intervention on family caregivers' PT of stroke patient dependency risk. This study is unique from two perspectives: (1) it is the first randomized controlled trial (RCT) achieving a high level of evidence (LoE) [26], and (2) this high-LoE RCT was conducted on the family caregivers' PT of stroke patient dependency risk for the first time in Iran. Family caregivers indirectly serve as a major component of the official healthcare systems, and recently, the national public health has made their support and evaluation a priority [27].

The results showed that the PT and its dimensions, i.e., the PS and intensity could significantly change through instruction. As can be seen in Table 3, the mean PS in the intervention group before the instruction was $37.93 \pm 11.08$ which saw a significant and persistent increase after the instructional intervention at all stages, such that the mean PS continued to be high even two months following the instructional intervention (48.77 \pm 2.58$)$. Similar results were obtained for the PI in that the mean of post-instruction PI increased significantly in the intervention group after two months (from postinstruction $39.20 \pm 11.68$ to $49.66 \pm 1.65$ ). No changes were observed in the control group which had not received the instructional intervention. The effect of instruction on the primary variable, i.e., the PT, was so significant in the intervention group that it remained unaffected by the passage of time. The Friedman test results pointed to a significant difference between the PT scores of the intervention group in pre- and all the stages of post-intervention $(\mathrm{P}<0.001)$. However, the PT scores of the control 
group saw a decrease immediately and two weeks after the intervention, in addition to a merely small increase two months after the intervention with no significant difference $(P=0.245)$.

The changes in the mean PI could also be viewed from a different perspective. The Mann-Whitney U test results pointed to no significant difference between the intervention and control groups regarding the pre-intervention family caregivers' $\mathrm{PT}(\mathrm{P}=0.591)$. However, a statistically significant increase was observed in the family caregivers' PT immediately, two weeks, and two months following the intervention in the intervention group compared with the control group $(\mathrm{P}<0.001)$.

In general, results demonstrated that the PT of stroke risks and its dimensions could be changed for the better through effective instruction, which corresponds to the results of the previous studies. The results of a study on the empowerment of stroke patients' family caregivers demonstrated that giving information about the disease and patient care skills would lead to an enhanced understanding about the patient's dependency and care needs [27]. Another study was also conducted by offering an instruction package to stroke patients' family caregivers at the hospital. Follow-up results up to three months after discharge indicated an improved understanding about the disease, patient's dependency risk, and a sense of satisfaction on the part of patients and family caregivers [28]. The effect of instructional short message service, based on the health belief model (HBM), on improving adherence to medication in stroke patients was investigated in another randomized controlled interventional study. The results suggested increasing adherence to medication and PT (PS and PS) of stroke risks [29]. The results of a study based on early problem-solving intervention for stroke caregivers through a one-year follow-up program demonstrated alleviated depression, lifestyle alteration, and enhanced health for family caregivers in the intervention group. The curve modeling results indicated that reinforced PT and rational problem-solving had mediatory effects on alleviating caregiver depression [30].

The effect of the instructional intervention on improving the PT of other disease risks was established in other studies. The results of an RTC indicated the positive effect of Health Belief Model-based instruction on improving type 2 diabetic patients' PT of the risks associated with not controlling this disease [31]. The HBM-based instructional intervention improved housewives' PT of gastric cancer risks and associated preventive behaviors [32]. The peer-assisted nutrition health instructional intervention based on HBM positively affected students' PT of unhealthy nutrition risks [33]. The findings analysis of HBM-based instructional interventions and the theory of planned behavior indicated an increase in the PT of the risks associated with not using condoms and risky sexual behaviors [34]. The results of an interventional study revealed that the HBM-based nursing intervention could enhance the PT of the risks of lack of disease management and its complications in the inability to perform ADLs in patients with chronic obstructive pulmonary disease (COPD) [35]. The comparison of an HBM-based RCT with the findings of a knowledge-based intervention in American men showed significant positive changes in the HBM-based instructional intervention group including the PT of the risks associated with not injecting the human papillomavirus vaccine (HPV) [36].

The results of the current study correspond to other studies conducted in Iran adopting the familycentered empowerment model (FCEM) to improve the awareness and PT of the non-professional caregivers. In the study by Alhani, increased knowledge and awareness of the disease as well as its complications and treatments enhanced the PT of the risk of iron deficiency in thalassemic children and their parents [19]. The study by Hakim et al., demonstrated the efficacy of FCEM on the understanding and the PT of the parents of infants undergoing ostomy surgery [20]. The study by Vahedian-Azimi et al., the implementation of FCEM increased the PT by family caregivers of myocardial infarction complications [21]. The implementation of FCEM increased the understanding and PT of the risks associated with asthma in parents of asthmatic children [22]. In addition, the implementation of FCEM positively affected the understanding and PT of multiple sclerosis patients' family caregivers [24]. 


\section{Conclusions}

The results showed that the PT and its dimensions, i.e., PS and PI could be changed through instruction. In other words, the PS, i.e., family caregiver's mental understanding of the risk of patient's dependency on family caregiver in ADLs, and the PI, i.e., family caregiver's mental understanding of the extent of damage induced by patient's dependency on the caregiver could be enhanced by instructing family caregivers. This may reduce patients' reliance and promote independence in their ADLs. It should not be overlooked that, although pre-discharge instructional interventions can help family caregivers assume new responsibility, they cannot address the various care needs of stroke patients single-handedly. Therefore, the development of affordable occupational therapy and rehabilitation centers and the support of relevant organizations can help these patients restore their independence.

It is the researchers' view that healthcare providers can benefit from the findings of this study in their instructional programs to improve the health of patients and family caregivers and promote the independence level of patients in their ADLs. In addition, it is recommended that further studies be conducted on the efficacy of PT in achieving patient independence and alleviating caring pressure. Some of the study limitations included the high vulnerability of stroke patients and the subsequent high attrition rate as well as the high anxiety levels of family caregivers in the hospitals disturbing their concentration on instructional materials to some extent.

Acknowledgments: The researchers feel obliged to express their gratitude to the Shahid Beheshti University of Medical Sciences' Vice-Chancellery of Research Affairs, the esteemed faculty members of the School of Nursing and Midwifery, and all stroke patients and their caregivers who cooperated with us in the data collection stage.

Author Contributions: P.V. conceived and designed the experiments; N.D. performed the experiments and wrote the paper; N.Sh. analyzed the data; C.R. and M.H. contributed analysis tools.

Conflicts of Interest: The researchers deny any conflict of interest and maintain that they all collaborated in the implementation and writing of this study.

\section{References}

1. Zorowitz, R.; Brainin, M. Advances in brain recovery and rehabilitation. Stroke, 2011, 42, 294-297, 10.1161/STROKEAHA.110.605063.

2. Thrift, A.G.; Cadilhac, D.A.; Thayabaranathan, T.; Howard, V.J.; Rothwell, P.M.; Donnan, G.A. Global stroke statistics. Int J Stroke, 2014, 9, 6-18. 10.1111/ijs.12245.

3. Salman-Roghani, R.; Delbari, A.; Tabatabae, S.S. Stroke rehabilitation: Principles, advances, early experiences, and realities in Iran. Journal of Sabzevar University of Medical Sciences, 2013, 19, 96-108. (Persian)

4. Philp, I.; Brainin, M.; Walker, M.F.; Ward, A.B.; Gillard, P.; Shields, A.L.; Norrving, B.; Global Stroke Community Advisory Panel. Development of a post stroke checklist to standardize follow-up care for stroke survivors. J Stroke Cerebrovasc Dis. 2013, 22, 173-80, 10.1016/j.jstrokecerebrovasdis.2012.10.016.

5. Rigby, H.; Gubitz, G.; Phillips, S. A systematic review of caregiver burden following stroke. Int J Stroke. 2009, 4, 285-92, 10.1111/j.1747-4949.2009.00289.x.

6. Mendis, S.H. Stroke disability and rehabilitation of stroke: World Health Organization perspective. Int J Stroke. 2013, 8, 3-4, 10.1111/j.1747-4949.2012.00969.x.

7. Collins, L.G.; Swartz, K. Caregiver Care. Am Fam Physician. 2011, 83, 1309-1317.

8. Dehghan-Nayeri, N.; Mohamadi, M.; Pedram-Razi, S.H.; Arazi, T.M.; Kazem-Nezhad, A. The effect of family empowerment program on adherence to the treatment Regime of patients with stroke. Journal of Evidence-Based Care. 2014, 5, 57-66, 10.22038/EBCJ.2015.4072. (Persian)

9. Hsueh, I.P.; Wang, C.H.; Liou, T.H.; Lin, C.H.; Hsieh, C.L. Test-retest reliability and validity of the comprehensive activities of daily living measure in patients with stroke. J Rehabil Med. 2012, 44, 637-41. 10.2340/16501977-1004

10. Hung, J.W.; Huang, Y.C.; Chen, J.H.; Liao, L.N.; Lin, C.J.; Chuo, C.Y. Factors associated with strain in informal caregivers of stroke patients. Chang Gung Med J, 2012, 35, 392-401. 
11. Miller, E.L.; Murray, L.; Richards, L.; Billinger, S.A; American Heart Association Council on Cardiovascular Nursing and the Stroke Council. Comprehensive overview of nursing and interdisciplinary rehabilitation care of the stroke patient: a scientific statement from the American Heart Association. Stroke. 2010, 41, 24022448, 10.1161/STR.0b013e3181e7512b.

12. Baumann, M.; Lurbe-Puerto, K.; Alzahouri, K.; Aïach, P. Increased residual disability among post stroke survivors and the repercussions for the lives of informal caregivers. Top Stroke Rehabil .2011, 18, 162-171, 10.1310/tsr1802-162.

13. Moeini, B.; Barati, M.; Jaliliyan, F. Factors associated with physical activity of functional independence in the elderly. Medical Journal of Hormozgan University. 2011, 15, 318-26. (Persian)

14. Saffari, M.; Shojaeizadeh, D.; Ghofranipour, F.; Heydarnia, A.; Pakpour, A.H. Health Education and Promotion Theories, Models and Methods, 2nd ed.; Sobhan: Tehran, Iran, 2012; pp. 53-63; 97-964-2580-47-7. (Persian)

15. Glanz, K.A.; Rimer, B.A.; Viswanath, K. Health Behavior and Health Education Theory, Research and Practice, 4th ed.; Josey-Bass Publisher: San Francisco, USA, 2008; pp. 45-50; 8-30. 978-0787996147.

16. DiClemente, R.J.; Salazar, L.F.; Crosby, R.A. Health Behavior Theory for Public Health, 1st ed.; Jones \& Bartlett Learning: Burlington, USA, 2013; pp. 83-86; 978-0763797539.

17. O'Toole, M.T. Mosby's Medical Dictionary; 9th ed.; Elsevier Mosby: Missouri, USA, 2009; pp. 53; 9780323085410

18. Schmid, K.; Muldoon, O.T. Perceived threat, social identification, and psychological well-being: The effects of political conflict exposure. Polit Psychol. 2013, 36, 1-18, 10.1111/pops.12073.

19. Alhani, F. Evaluating of Family-Centered Empowerment Model on Preventing Iron Deficiency Anemia. Ph.D Dissertation, Tarbiat Modares University, Tehran, Iran, 2003. (Persian)

20. Hakim, A.; Palizban, E.; Ahmadi-Angali, K. The effect of family-centered empowerment model on the level of parents' knowledge of children with ostomy. Iran J Pediatr. 2015; 4, 22-31. (Persian)

21. Vahedian-azimi, A.; Alhani, F.; Gohari-mogaddam, K.; Madani, S.J.; Naderi, A.; Hajiesmaeili, M. Effect of family-centered empowerment model on the quality of life in patients with myocardial infarction: a clinical trial study. Journal of Nursing Education. 2015, 4, 8-22. (Persian)

22. Teymouri, F.; Alhani, F.; Kazemnejad, A. The effect of the family-centered empowerment model on the quality of life in parents of children with asthma. Sci J Hamadan Nurs Midwifery Fac. 2014, 22, 5-14. (Persian)

23. Sanaie, N.; Nejati, S.; Zolfaghari, M.; Alhani, F.; Kazem-Nezhad, A. The effect of family-centered empowerment in self efficacy and self-esteem in patients undergoing coronary bypass graft surgery. Journal of Research Development in Nursing \& Midwifery. 2014, 11, 44-53. (Persian)

24. Masoodi, R.; Alhani, F.; Moghadassi, J.; Ghorbani, M. The effect of family-centered empowerment model on skill, attitude, and knowledge of multiple sclerosis caregivers. Journal of Birjand University of Medical Sciences. 2011, 17, 97-87. (Persian)

25. Azimi, R.; Mohammadi, F.; Hosseini, M.A.; Farzi, M. The impact of home-based rehabilitation on the quality of life of patients with stroke and their family caregiver's burdon of care. Evidence Based Care Journal. 2013, 3, 85-77, 10.22038/EBCJ.2013.729. (Persian)

26. Polit, D.F.; Beck, C.T. Nursing Research Generating and Assessing Evidence for Nursing Practice. $9^{\text {th }}$ ed.; Wolters Kluwer Health: Lippincott Wiliams \& Wilkins, 2012; pp. 20-28; 978-1605477084.

27. Bakas, T.; Farran, C.J.; Austin, J.K.; Given, B.A.; Johnson, E.A.; Williams, L.S. Stroke caregiver outcomes from the telephone assessment and skill-building it (TASK). Top Stroke Rehabil. 2009, 16, 105-121, 10.1310/tsr1602-105.

28. Eames, S.; Hoffmann, T.; Worrall, L.; Read, S.; Wong, A. Randomised controlled trial of an education and support package for stroke patients and their carers. BMJ Open. 2013, 3, e002538, 10.1136/bmjopen-2012002538.

29. Kamran-Kamal, A.; Shaikh, Q.; Pasha, O.; Azam, L.; Islam, M.; Memon, A.A; Rehman, H.; Ahmed-Akram, M.; Affan, M.; Nazir, S.; et al. A randomized controlled behavioral intervention trial to improve medication adherence in adult stroke patients with prescription tailored Short Messaging Service (SMS)-SMS4Stroke study. BMC Neurol. 2015, 15, 1-11, 10.1186/s12883-015-0471-5.

30. King, R.B.; Hartke, R.J.; Houle, T.; Lee, J.; Herring, G.; Alexander-Peterson B.S.; Raad, J. A problem-solving early intervention for stroke caregivers: One year follow-up. Rehabil Nurs. 2012, 37, 231-243, 10.1002/rnj.039.

31. Bayat, F.; Shojaeezadeh, D.; Baikpour, M.; Heshmat, R.; Baikpour, M. The effects of education based on extended health belief model in type 2 diabetic patients: a randomized controlled trial. J Diabetes Metab Disord. 2013, 12, 3-6, 10.1186/2251-6581-12-45. 
351 352 353 354 355 356 357 358 359 360 361 362 363 364
32. Alidosti, M.; Sharifirad, G.R.; Golshiri, P.; Azadbakht, L.; Hasanzadeh, A.; Hemati, Z. An investigation on the effect of gastric cancer education based on Health Belief Model on knowledge, attitude and nutritional practice of housewives. Iran J Nurs Midwifery Res. 2012, 17, 256-262.

33. Lotfi-Mainbolagh, B.; Rakhshani, F.; Zareban, I.; Montazerifar, F.; Alizadeh-Sivaki, H.; Alizadeh-Sivaki, H.; Parvizi, Z. The effect of peer education based on health belief model on nutrition behaviors in primary school boys. J Res Health Sci. 2012, 2, 1-4.

34. Montanaro, E.A.; Bryan, A.D. Comparing theory-based condom interventions: health belief model versus theory of planned behavior. Health Psychol. 2014, 33, 1251-1260, 10.1037/a0033969.

35. Wang, Y.; Zang, X.Y.; Bai, J.; Liu, S.Y.; Zhao, Y.; Zhang, Q. Effect of a Health Belief Model-based nursing intervention on Chinese patients with moderate to severe chronic obstructive pulmonary disease: a randomized controlled trial. J Clin Nurs. 2014, 23, 1342-1353, 10.1111/jocn.12394.

36. Mehta, P.; Sharma, M.; Lee, R. Designing and evaluating a health belief model-based intervention to increase intent of HPV vaccination among college males. Int $Q$ Community Health Educ. 2014, 34, 101-117, 10.2190/IQ.34.1.h. 